\title{
Factores predictores de formas graves de COVID-19 que requieren hospitalización en pacientes con diabetes mellitus
}

\author{
Predictor factors of severe forms of COVID-19 requiring hospitalisation \\ in patients with diabetes mellitus
}

\begin{abstract}
${ }^{1}$ Antía Fernández-Pombo, ${ }^{1}$ Alicia Santamaría-Nieto, ${ }^{1,4} \mathrm{Gemma}$ Rodríguez-Carnero, ${ }^{2}$ Olaia Díaz-Trastoy, ${ }^{1}$ Paula AndújarPlata, ${ }^{3}$ Carlos Rábade-Castedo, ${ }^{1}$ Alberto Pena-Dubra, ${ }^{1}$ Rocío Villar-Taibo

${ }^{1}$ Department of Endocrinology and Nutrition, Complejo Hospitalario Universitario de Santiago de Compostela, Universidad de Santiago de Compostela, Spain. ${ }^{2}$ Department of Endocrinology and Nutrition. University Hospital of Pontevedra, Spain. ${ }^{3}$ Department of Pneumology. University Clinical Hospital of Santiago de Compostela, Spain.

${ }^{4}$ Epigenomics in Endocrinology and Nutrition Group, Instituto de Investigacion Sanitaria de Santiago (IDIS)
\end{abstract}

\begin{abstract}
Aims: To identify possible risk factors of hospitalisation in patients with diabetes (DM) and 2019 novel coronavirus disease (COVID-19), to establish the prevalence of DM among infected patients and that of DM in patients requiring hospitalisation.

Research design and methods: Between March-May 2020, 1202 consecutive subjects in the healthcare area of Santiago de Compostela and Barbanza (Galicia, Spain) were diagnosed with COVID-19, among whom 136 patients with DM were identified. Demographic data, DM characteristics and complications during hospitalisation were collected and analysed.

Results: The prevalence of DM among COVID-19 infected subjects was $11.3 \%$. This ascended to $21.7 \%$ in inpatients, while only $8.1 \%$ of outpatients had DM $(p<0.0001)$.

Higher levels of glycated haemoglobin significantly increased the risk of hospitalisation (OR: 1.57; $95 \% \mathrm{Cl}: 1.03-2.41, \mathrm{p}=0.037$ ), with small differences making the difference between inpatients and outpatients ( $7.3 \pm 1.3 \%$ vs $6.8 \pm 0.9 \%$ [ $56 \pm 14$ vs $51 \pm 10 \mathrm{mmol} / \mathrm{mol}$ ], respectively, $p=0.009$ ). 0 besity $(\mathrm{BMl} \geq 30 \mathrm{~kg} / \mathrm{m} 2)$ was the only comorbidity associated to hospitalization (OR: 2.94; $95 \% \mathrm{Cl}: 1.17-7.30, \mathrm{p}=0.021)$. There were no differences in the type and duration of DM, the type of glucose-lowering drugs, or in the presence of micro/macrovascular complications.

Conclusion: DM does not increase the risk of suffering from COVID-19, but it can worsen the outcome, raising the hospitalisation rate. Thus, obesity and worse chronic glycaemic control, even with small variations, are independent and determining factors for severe forms which require hospitalisation.

Keywords: COVID-19, SARS-CoV-2, diabetes, hospitalisation.
\end{abstract}

\section{INTRODUCTION}

In December 2019 a new coronavirus (SARS-CoV-2), causing a severe acute respiratory syndrome (COVID-19), emerged in China and rapidly spread around the world ${ }^{1}$. Thus, on 11 March 2020 the World Health Organization declared COVID-19 a global pandemic. It is characterized by fever, cough, fatigue and shortness of breath, and while most patients have mild symptoms ${ }^{2}$, the disease can also cause pneumonia and multiple organ dysfunction syndrome, with a fatality rate of $1-5 \% 3,4$. It has been shown that hospitalised patients with COVID-19 have some type of comorbidity in $20-51 \%$ of the cases ${ }^{5,6}$ which has also been correlated with poorer clinical outcomes $^{7}$. Diabetes mellitus (DM) is considered to be one of the most commonly associated comorbidities. Although DM generally confers an increased risk for infection, these are mainly fungal and bacterial and, therefore, several studies have shown that the prevalence of diabetes in patients with COVID-19 is similar to the general population ${ }^{7,8}$. However, a higher prevalence of diabetes is seen in patients with severe COVID-199, with these subjects presenting higher rates of hospitalisation ${ }^{10}$, higher rates of admission to intensive care unit (ICU) and increased risk of the use of invasive ventilation or death ${ }^{11}$. This fact could be explained in part due to concomitant factors associated to DM. Thus, the prevalence of diabetes increases with age, which is itself a risk factor for severe clinical course ${ }^{9}$. On the other hand, patients with DM usually present a greater prevalence of other comorbidities, such as hypertension, obesity, cardiovascular disease and cerebrovascular disease $\mathrm{e}^{12}$, making it unclear whether DM is an independent predictor for severity in COVID-19.

Furthermore, it appears that there are other mechanisms which contribute to the risk of severe COVID-19 in patients with DM. One of the proposed hypotheses is the expression of angiotensin-converting enzyme 2 (ACE2), which seems to be increased in subjects with DM and may be a site of attachment of the virus. Furin is another molecule involved in viral entry and its expression could also be increased. On the other hand, it is also known that in patients with DM the immune response is impaired, which could cause an exacerbated inflammatory response ${ }^{13}$.

Regarding the characteristics of DM and its relation with the severity of the disease, poor glycaemic control upon hospital admission and during the hospital stay has shown to be a risk factor of worse outcomes in patients with COVID-199. However, while in some studies a higher level of glycated haemoglobin $(\mathrm{HbA1C})$ was related with worse prognosis ${ }^{14}$, this has not been confirmed in other series ${ }^{15}$. In addition, to date, there are also limited data on the type and duration of diabetes and the effect of glucose-lowering drugs on the course of the disease. Thus, although studies about 
COVID-19 are increasing rapidly, there is still much to be learned about the characteristics of patients with COVID-19 and DM, the risk factors for hospitalisation and severe clinical course, including antihyperglycaemic treatment.

The aim of this study was to describe a series of patients with COVID-19 and DM, exploring the differences between inpatients and outpatients to identify those at higher risk of developing severe forms of COVID-19 which require hospital admission, as well as to describe the clinical course of hospitalised patients, therefore contributing to the understanding of the relation between DM and COVID-19.

\section{RESEARCH DESIGN AND METHODS}

\section{Study design}

This is a retrospective cross-sectional study performed in the healthcare area of Santiago de Compostela and Barbanza (Galicia, Spain), with a total population of 446,798 patients ${ }^{16}$.

The data from the medical records of patients with COVID-19 and DM in our healthcare area between March and May 2020 were evaluated. Patients were included in our study when both conditions, DM and infection by SARS-CoV-2 confirmed by microbiological analysis with positive Polymerase Chain Reaction (PCR), were present. Patients with a positive lgM result in a rapid serology test but with negative PCR (suspicion of false positive) were excluded. The hospital's Ethics and Clinical Research Committee approved the study protocol, and patient anonymity was preserved.

The primary objective was to describe a series of patients with COVID-19 and DM and explore the differences between inpatients and outpatients, in order to detect high-risk factors for hospital admission. Secondary objectives included establishing the global prevalence of DM among subjects infected with SARS-CoV-2 in our healthcare area, comparing demographic parameters and hospitalisation rate among patients with COVID-19 and DM vs. non-DM population, and finally to analyse the evolution of COVID-19 throughout hospital stay in the subgroup of inpatients with DM.

\section{Data collection}

Study parameters included baseline demographic variables and DM characteristics (age, sex, comorbidities, type and duration of DM, presence of macro and microvascular complications, use of glucose-lowering drugs and current metabolic control measured as the most recent $\mathrm{HbA1c}$ value, prior to admission in the case of hospitalised subjects). In the subgroup of patients who required hospitalisation, the length of stay, the development of complications during hospital stay and the severity of the respiratory infection (presence or absence of respiratory failure and pneumonia) were also evaluated. In addition, the need for admission to an intensive care unit and percentage of deaths were recorded.

\section{Statistical analysis}

All statistical analyses were performed with the SPSS 22.0 program (Chicago, Illinois; USA). Data are expressed as mean and standard deviation or median and interquartile range (IR) for quantitative variables. Categorical variables are expressed as numbers and percentages. The hypothesis of a normal distribution was verified by the Kolmogorov-Smirnov test. The T-test was used to compare a quantitative variable in two groups. The $x 2$ test was used to compare qualitative variables. Predictors of hospital admission in patients with DM and COVID-19 were analysed, for which a multivariate analysis was carried out using a binary logistic regression model. The level of significance was set at $p<0.05$.

\section{RESULTS}

Between March and May 2020, a total of 1202 patients were diagnosed with COVID-19 in our healthcare area. The demographic data and information regarding the type of health care required by these patients are summarized in Figure 1. Thus, the demographic profile of the inpatient was an elderly male, while outpatients were predominantly females who were more than a decade younger than hospitalised patients (mean age 65.1 years-old for inpatients vs. 53.6 years-old for outpatients, $p<0.0001 ; 54.6 \%$ male inpatients vs. $39.5 \%$ male outpatients; $p<0.0001)$.

Of the total number of COVID-19 positive patients, 136 subjects with DM were identified, constituting our study population. Therefore, the prevalence of DM among COVID-19 infected patients was $11.3 \%$. The presence of DM also differed between hospitalised patients and outpatients. Thus, the prevalence of DM ascended to $21.7 \%$ in inpatients, while only $8.1 \%$ of outpatients were had DM $(p<0.0001)$.

In comparison with the non-DM population, COVID-19 infected patients with DM exhibited several particularities. First of all, gender distribution differences were evident, with a greater prevalence of males in the DM group with respect to

Figure 1. Demographics of the COVID-19 population in our healthcare area.

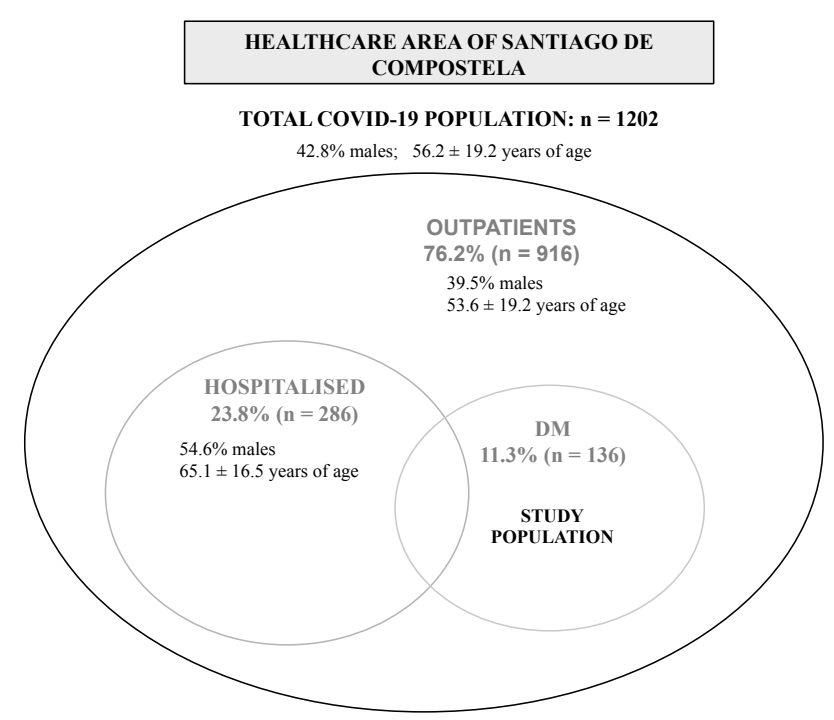

DM: diabetes mellitus. 
Table 1. Baseline characteristics of patients with COVID-19 infection and DM.

\begin{tabular}{|c|c|c|c|}
\hline $\begin{array}{l}\text { DM and COVID population } \\
(n=136)\end{array}$ & $\begin{array}{l}\text { Inpatients } \\
(\mathrm{n}=62)\end{array}$ & $\begin{array}{l}\text { Outpatients } \\
\qquad(\mathrm{n}=74)\end{array}$ & $p$ value \\
\hline Gender (\% male) & $69.4 \%$ & $52.7 \%$ & ${ }^{\star} 0.048$ \\
\hline Age (years) & $70.0 \pm 10.6$ & $73.0 \pm 12.6$ & 0.141 \\
\hline $\begin{array}{l}\text { Type of DM: n (\%) } \\
\text { - Type } 1 \\
\text { - Type } 2 \\
\text { - Steroid-induced } \\
\text { - NODAT } \\
\text { - Pancreatopathy } \\
\text { - Unknown }\end{array}$ & $\begin{array}{c}1(1.6 \%) \\
55(88.7 \%) \\
3(4.8 \%) \\
2(3.2 \%) \\
1(1.6 \%) \\
0\end{array}$ & $\begin{array}{c}1(1.4 \%) \\
72(97.3 \%) \\
0 \\
0 \\
0 \\
1(1.4 \%)\end{array}$ & 0.115 \\
\hline Duration of DM (years) & $9.1 \pm 8.5$ & $10.1 \pm 8.0$ & 0.503 \\
\hline Metabolic control (HbA1c) & $\begin{array}{c}7.3 \pm 1.3 \% \\
(56 \pm 14 \\
\mathrm{mmol} / \mathrm{mol})\end{array}$ & $\begin{array}{c}6.8 \pm 0.9 \% \\
(51 \pm 10 \\
\mathrm{mmol} / \mathrm{mol})\end{array}$ & ${ }^{*} 0.009$ \\
\hline $\begin{array}{l}\text { DM treatment: } n(\%) \\
\text { - Insulin } \\
\text { - Metformin } \\
\text { - DPP-4 inhibitors } \\
\text { - SGLT2 inhibitors } \\
\text { - GLP-1 receptor agonists } \\
\text { - Sulphonylureas } \\
\text { - Pioglitazone } \\
\text { - Repaglinide } \\
\text { - Acarbose }\end{array}$ & $\begin{array}{c}20(32.3 \%) \\
36(58.1 \%) \\
17(27.4 \%) \\
8(12.9 \%) \\
2(3.2 \%) \\
5(8.1 \%) \\
0 \\
2(3.2 \%) \\
0\end{array}$ & $\begin{array}{c}16(21.6 \%) \\
49(66.2 \%) \\
25(33.8 \%) \\
13(17.6 \%) \\
1(1.4 \%) \\
7(9.5 \%) \\
0 \\
4(5.4 \%) \\
0\end{array}$ & $\begin{array}{l}0.161 \\
0.345 \\
0.465 \\
0.433 \\
0.591 \\
0.756 \\
---- \\
0.687 \\
-----\end{array}$ \\
\hline $\begin{array}{l}\text { Complications: n (\%) } \\
\text { - Retinopathy } \\
\text { - Nephropathy } \\
\text { - Neuropathy } \\
\text { - Ischemic cardiopathy } \\
\text { - Stroke } \\
\text { - Peripheral arteriopathy }\end{array}$ & $\begin{array}{c}6(9.7 \%) \\
13(21.0 \%) \\
6(9.7 \%) \\
12(19.4 \%) \\
2(3.2 \%) \\
6(9.7 \%)\end{array}$ & $\begin{array}{c}10(13.5 \%) \\
12(16.2 \%) \\
2(2.7 \%) \\
10(13.5 \%) \\
7(9.5 \%) \\
7(9.5 \%)\end{array}$ & $\begin{array}{l}0.404 \\
0.576 \\
0.145 \\
0.394 \\
0.176 \\
0.993\end{array}$ \\
\hline $\begin{array}{l}\text { Comorbidities: n (\%) } \\
\text { - Hypertension } \\
\text { - Dyslipidemia } \\
\text { - Obesity } \\
\text { - Sleep apnea }\end{array}$ & $\begin{array}{c}42(67.7 \%) \\
49(79.0 \%) \\
40(64.5 \%) \\
5(8.1 \%)\end{array}$ & $\begin{array}{c}54(73.0 \%) \\
54(73.0 \%) \\
31(41.9 \%) \\
5(6.8 \%)\end{array}$ & $\begin{array}{c}0.505 \\
0.412 \\
{ }^{\star} 0.043 \\
0.788\end{array}$ \\
\hline $\begin{array}{l}\text { Tobacco use: n (\%) } \\
\text { - Current smoker } \\
\text { - Former smoker } \\
\text { - Non-smoker } \\
\text { - No data }\end{array}$ & $\begin{array}{c}2(3.2 \%) \\
20(32.3 \%) \\
38(61.3 \%) \\
2(3.2 \%)\end{array}$ & $\begin{array}{c}3(4.1 \%) \\
9(12.2 \%) \\
60(81.1 \%) \\
2(2.7 \%)\end{array}$ & ${ }^{*} 0.015$ \\
\hline
\end{tabular}

$$
" p<0.05
$$

DM: diabetes mellitus; NODAT: new onset diabetes after transplantation; HbA1c: glycated haemoglobin; DPP-4. dipeptidyl peptidase-4; SGLT2: sodium-glucose co-transporter-2; GLP1: glucagon-like peptide-1. the non-DM group (59.9\% vs. $40.4 \% ; p<0.0001)$. Mean age was also higher than in the non-diabetic group, being $71.6 \pm 11.8$ years of age for DM patients and $54.1 \pm 19.1$ years of age for non-DM patients $(p<0.001)$. In addition, the hospitalisation rate was higher among patients with DM compared to non-DM subjects ( $45.3 \%$ vs. $21.0 \%$, respectively; $p<0.0001)$.

The comparison of baseline demographic parameters, characteristics, micro and macrovascular complications, comorbidities and treatment of DM between inpatients and outpatients are described in Table 1. The percentage of admitted males was significantly higher, yet no differences were observed in terms of age. There were also no differences in the type and duration of DM or in the type of glucose-lowering drugs used. Patients with DM who required admission did not present a greater number of micro or macrovascular complications, and in terms of associated comorbidities, only obesity constituted a differentiating element in both groups (64.5\% of inpatients, and $41.9 \%$ of outpatients, $p=0.043$ ).

In the multivariate analysis, in addition to obesity (body mass index $\geq 30 \mathrm{~kg} / \mathrm{m}^{2}$ ), a worse metabolic control prior to admission was also a risk factor associated with higher levels of hospitalisation in patients with DM (Table 2). In fact, small differences in $\mathrm{HbA} 1 \mathrm{c}$ have made the difference between inpatients and outpatients $(7.3 \pm 1.3 \%$ vs $6.8 \pm 0.9 \%$ [56 \pm 14 vs $51 \pm 10 \mathrm{mmol} / \mathrm{mol}$, respectively, $p=0.009$ ).

Regarding the evolution of inpatients, the median hospital stay for subjects with COVID-19 and DM was 13 days and the range was 97 days (between 3 and 100). The complications and outcomes of these patients during their hospitalisation are summarized in Table 3. Twenty-three subjects (37.1\%) experienced hyperglycaemic decompensation and $11(17.7 \%)$ required intensive care.

\section{DISCUSSION}

The present study has shed light on the differences between hospitalised patients and outpatients with DM and COVID-19, identifying several risk factors that can lead to hospital admission in these subjects. A worse metabolic control of DM places COVID-19 patients at high-risk of severe disease, leading to hospitalisation and eventual complications. In fact, in our study we could observe that even small differences in HbA1c seem to matter.

However, despite this association between DM and worse outcomes in COVID-19 patients, the susceptibility to SARS-CoV-2 infection may not be higher in these subjects. A meta-analysis of 12 studies collecting data from 2108 Chinese patients with COVID-19 reported a prevalence of DM of $10.3 \%{ }^{8}$, which was similar to the nationwide prevalence of $10.9 \%$ reported in $2013^{17}$. In our study, the prevalence of DM among COVID-19 infected subjects was $11.3 \%$, which is, therefore, in concordance with the prevalence estimated in other series and slightly lower than the 2012 estimate in Spain ${ }^{18}$. 
Table 2. Risk factors associated to hospitalization in patients with DM.

\begin{tabular}{|l|c|c|}
\hline & OR $(95 \% \mathrm{Cl})$ & p value \\
\hline Age & $1.01(0.90-1.05)$ & 0.580 \\
\hline Gender (male) & $0.69(0.27-1.47)$ & 0.435 \\
\hline Hypertension & $0.70(0.26-1.86)$ & 0.470 \\
\hline Obesity & $2.94(1.17-7.30)$ & ${ }^{\star} 0.021$ \\
\hline Ischemic cardiopathy & $1.20(0.30-4.06)$ & 0.750 \\
\hline Stroke & $0.40(0.06-2.73)$ & 0.350 \\
\hline Atherosclerosis & $0.55(0.12-2.50)$ & 0.450 \\
\hline Sleep apnea & $0.69(0.13-3.55)$ & 0.650 \\
\hline Smoker & $1.74(0.90-2.70)$ & 0.110 \\
\hline HbA1c & $1.57(1.03-2.41)$ & ${ }^{\star} 0.037$ \\
\hline
\end{tabular}

OR: odds ratio; Cl: confidence interval; HbA1c: glycated haemoglobin.

Table 3. Complications and outcomes of patients with DM and COVID-19 during hospital stay.

\begin{tabular}{|l|c|}
\hline Complication/Outcome & $\mathrm{n}(\%)$ \\
\hline Pneumonia & $36(58.1 \%)$ \\
\hline Respiratory insufficiency & $19(30.6 \%)$ \\
\hline Hypoxemia & $28(45.2 \%)$ \\
\hline Hyperglycaemic decompensation & $23(37.1 \%)$ \\
\hline ICU hospitalization & $11(17.7 \%)$ \\
\hline $\begin{array}{l}\text { Other complications detected } \\
\text { - Acute kidney failure or exacerbated chronic } \\
\text { kidney failure }\end{array}$ & $8(12.9 \%)$ \\
- Urinary tract infection & $3(4.8 \%)$ \\
- Candidiasis & $3(4.8 \%)$ \\
\hline Death & $1(1.6 \%)$ \\
\hline
\end{tabular}

When it comes to determining the prevalence of DM in COVID-19 patients requiring hospitalisation, the results are diverse. While in an Italian study conducted among 146 hospitalised patients with confirmed SARS-CoV-2 infection, the prevalence of DM was only $8.9 \%$ (mean age 65.3 years) ${ }^{8}$, in a Chinese study conducted among 174 hospitalised patients with COVID-19 (median age 59 years) the prevalence of DM was $21.2 \%{ }^{19}$, which goes in the same direction as our study, where the prevalence of DM ascended to $21.7 \%$ in inpatients.

Thus, DM may not increase the risk of SARS-CoV-2 infection, but it can worsen the outcome, raising the hospitalisation rate, as we have observed, as well as the need for intensive care ${ }^{20}$. It is important to note that DM and uncontrolled glycaemia have already been reported as significant predictors of severity in patients infected with different viruses, including the Pandemic Influenza A (H1N1), Severe Acute Respiratory Syndrome (SARS) coronavirus and Middle East Respiratory Syndrome-related coronavirus (MERS-CoV) ${ }^{21-23}$. In fact, the presence of DM tripled the risk of hospitalization during the H1N1 infection outbreak in 200924. Thus, it is not surprising that something similar occurs with SARS-CoV-2.
There are several studies reporting data comparing disease severity between COVID-19 patients with and without $\mathrm{DM}^{19,25-27}$. However, to date, there are limited data on the type and duration of DM, the effect of glucose-lowering drugs or chronic glycaemic control prior to admission. In this sense, in a recent multicenter analysis of 7337 cases of COVID-19 including 952 patients with pre-existing type $2 \mathrm{DM}$, it was found that those with well-controlled blood glucose regulation fared much better than those with poorly controlled blood glucose (upper limit > $10 \mathrm{mmol} / \mathrm{L}$ ). In fact, a $0.8 \%$ ( $8 \mathrm{mmol} / \mathrm{mol}$ ) difference in $\mathrm{HbA} 1 \mathrm{c}$ made a marked difference in COVID-related outcomes ${ }^{14}$. In our study we confirm these findings, providing evidence of the association of the HbA1C value with the course of COVID-19. Considering the high prevalence of other comorbidities (such as cardiovascular disease, obesity and hypertension) in patients with DM, it remained unclear whether DM contributes independently to this increased risk of severity. However, according to our results, poor chronic glycaemic control may be an independent predictor of hospitalisation in patients with SARS-CoV-2 infection, and small differences in $\mathrm{HbA1C}$ may improve the outcomes. On the other hand, it is known that adiposity affects both the adaptive and the innate immune system with the development of chronic systemic inflammation ${ }^{28}$. Considering that $\mathrm{DM}$ and obesity are triggers to a cytokine storm, the presence of COVID-19 infection would have a worse inflammatory effect on individuals with both DM and obesity, as we could observe with the higher hospitalisation rate in those patients with DM who presented a body mass index $\geq$ $30 \mathrm{~kg} / \mathrm{m}^{2}$.

Finally, regarding glucose-lowering drugs, there is no consistent data in the literature on their differential effects on patients with COVID-19. It has been shown that dipeptidyl peptidase-4 (DPP-4) is the primary receptor of MERS$\mathrm{CoV}^{23}$. Thus, the relationship of coronaviruses to this cellular type-II transmembrane protein has generated great interest. Although ACE2 is recognized as the main receptor for SARS-CoV-2, a recent modelling study did not rule out its interaction with DPP4 ${ }^{29}$. However, at present, there is insufficient evidence either for or against the use of DPP-4 inhibitors in patients with diabetes and COVID-1930-31. In addition, the glucagon-like peptide- 1 receptor agonist liraglutide was shown to counteract the downregulating effect of DM on the pulmonary expression of ACE2 in rats without influencing glucose and insulin levels ${ }^{32}$. However, no differences among the type of glucose-lowering drug used, nor the type and duration of DM, were found in our study between admitted patients and outpatients.

The main limitations of this study are its retrospective design and the lack of a comparative group to evaluate differences in hospital evolution between COVID-19 admitted patients with and without DM. However, our study has certain strengths, such as the size of our sample, which included all the patients in the healthcare area with COVID-19 and DM, thus avoiding the risk of inclusion bias. Also, we have de- 
scribed the different profiles of patients with COVID-19 and DM regarding its management (as outpatients or inpatients), identifying certain factors which may increase the risk of admission in this population.

In conclusion, patients with DM do not appear to be at increased risk of contracting SARS-CoV-2 compared to the general population, but their worse chronic metabolic control is a determining and independent factor for developing severe forms of COVID-19 which require hospitalisation for more intensive treatment. In fact, even small differences in $\mathrm{HbA1C}$ seem to matter, making the difference between inpatients and outpatients. In addition, while obesity was found to be a risk factor of hospitalisation in patients with DM, there was no relation with other comorbidities. Neither did the type and duration of DM and the type of glucose-lowering drugs used influence the risk of admission. Thus, this study provides relevant insights into the relation between the characteristics of DM and COVID-19 severity, but there is still much to be learned and further studies in this regard are needed.

\section{CONFLICTO DE INTERESES Y FUENTES DE FINANCIACIÓN}

Funding: This study was not subject to any funding from public or private entities.

Conflicts of interest: The authors declare that there is no conflict of interest that could be perceived as directly or indirectly prejudicing the impartiality of the research reported.

Availability of data and material: We acknowledge that all data and materials, as well as software application, support our reported findings and comply with field standards. Data and study material are not publicly available, but are available from the corresponding author upon reasonable request, ensuring data transparency.

Ethics approval: The Ethics and Clinical Research Committee of our Hospital approved the study protocol, and was in compliance with the Helsinki Declaration. Patient anonymity was preserved. All data were treated in a pseudonymized way, ensuring technical and functional separation between the research team and the person in charge of the pseudonymization.

Authors' contributions: All authors contributed to study conception and design, followed-up patients, researched, analyzed and interpreted data, and reviewed and edited the manuscript.

All authors critically revised the final version of the manuscript and approved it for submission and subsequent potential publication.

\section{REFERENCES}

1. Wu Z, McGoogan J. Characteristics of and Important Lessons From the Coronavirus Disease 2019 (COVID-19) Outbreak in China: Summary of a Report of 72314 Cases From the Chinese Center for Disease Control and Prevention. JAMA. 2020. Online ahead of print.

2. Guan WJ, Ni ZY, Hu Y, Liang WH, Ou CQ, He JX, et al. Clinical Characteristics of Coronavirus Disease 2019 in China. N Engl J Med. 2020;382(18):1708-1720.

3. Li LQ, Huang T, Wang YQ, Wang ZP, Liang Y, Huang TB, et al. COVID-19 patients' clinical characteristics, discharge rate, and fatality rate of meta-analysis. J Med Virol. 2020;92(6):577-583.

4. Baud D, Qi X, Nielsen-Saines K, Musso D, Pomar L, Favre G. Real estimates of mortality following COVID-19 infection. Lancet Infect Dis. 2020;20(7):773.

5. Huang C, Wang Y, Li X, Ren L, Zhao J, Hu Y, et al. Clinical features of patients infected with 2019 novel coronavirus in Wuhan, China. Lancet. 2020;395(10223):497-506.

6. Chen N, Zhou M, Dong X, Qu J, Gong F, Han Y, et al. Epidemiological and clinical characteristics of 99 cases of 2019 novel coronavirus pneumonia in Wuhan, China: a descriptive study. Lancet. 2020;395(10223):507-513.
7. Guan WJ, Liang WH, Zhao Y, Liang HR, Chen ZS, Li YM, et al; China Medical Treatment Expert Group for COVID-19. Comorbidity and its impact on 1590 patients with COVID-19 in China: a nationwide analysis. Eur Respir J. 2020;55(5):2000547.

8. Fadini GP, Morieri ML, Longato E, Avogaro A. Prevalence and impact of diabetes among people infected with SARS-CoV-2. J Endocrinol Invest. 2020;43(6):867869

9. Apicella M, Campopiano MC, Mantuano M, Mazoni L, Coppelli A, Del PratoS. COVID-19 in people with diabetes: understanding the reasons for worse outcomes. Lancet Diabetes Endocrinol. 2020;8(9):782-792.

10. Petrilli CM, Jones SM, Yang J, Rajagopalan H, O'Donnell L, Chernyak Y, et al. Factors associated with hospital admission and critical illness among 5279 people with coronavirus disease 2019 in New York City: prospective cohort study. BMJ. 2020;369:m1966.

11. Roncon L, Zuin M, Rigatelli G, Zuliani G. Diabetic patients with COVID-19 infection are at higher risk of ICU admission and poor short-term outcome. J Clin Virol. 2020;127:104354.

12. Shi $Q$, Zhang X, Jiang F, Zhang X, Hu N, Bimu C, et al. Clinical Characteristics and Risk Factors for Mortality of COVID-19 Patients With Diabetes in Wuhan, China: A Two-Center, Retrospective Study. Diabetes Care. 2020;43(7):1382-1391.

13. Muniyappa R, Gubbi S. COVID-19 pandemic, coronaviruses, and diabetes mellitus. Am J Physiol Endocrinol Metab. 2020;318(5):E736-E741.

14. Zhu L, She ZG, Cheng X, Qin JJ, Zhang XJ, Cai J, et al. Association of Blood Glucose Control and Outcomes in Patients with COVID-19 and Pre-existing Type 2 Diabetes. Cell Metab. 2020;31(6):1068-1077.e3.

15. Cariou B, Hadjadj S, Wargny M, Pichelin M, Al-Salameh A, Allix I, et al; CORONADO investigators. Phenotypic characteristics and prognosis of inpatients with COVID-19 and diabetes: the CORONADO study. Version 2. Diabetologia. 2020;63(8):15001515.

16. Memoria 2018. Sistema Público de Saúde de Galicia (electronic publication). Edición 2018. Accesed September 2, 2020 at https://www.sergas.es/A-nosaorganizacion/Documents/832/MemoriaActividade2018.pdf.

17. Wang $L$, Gao $P$, Zhang $M$, Huang Z, Zhang $D$, Deng Q, et al. Prevalence and ethnic pattern of diabetes and prediabetes in China in 2013. JAMA. 2017;317:25152523.

18. Soriguer F, Goday A, Bosch-Comas A, Bordiú E, Calle-Pascual A, Carmena R, et al. Prevalence of diabetes mellitus and impaired glucose regulation in Spain: the Di@ bet.es study. Diabetologia. 2012;55(1):88-93.

19. Guo W, Li M, Dong Y, Zhou H, Zhang Z, Tian C, et al. Diabetes is a risk factor for the progression and prognosis of COVID-19. Diabetes Metab Res Rev. 2020;e3319.

20. Peric S, Stulnig TM. Diabetes and COVID-19: Disease-Management-People. Wien Klin Wochenschr. 2020;132(13-14):356-361.

21. Yang JK, Feng Y, Yuan MY, Yuan SY, Fu HJ, Wu BY, et al. Plasma glucose levels and diabetes are independent predictors for mortality and morbidity in patients with SARS. Diabet Med. 2006;23(6):623e8.

22. Schoen K, Horvat N, Guerreiro NFC, de Castro I, de Giassi KS. Spectrum of clinical and radiographic findings in patients with diagnosis of $\mathrm{H} 1 \mathrm{~N} 1$ and correlation with clinical severity. BMC Infect Dis. 2019;19(1):964.

23. Song Z, Xu Y, Bao L, Zhang L, Yu P, Qu Y, et al. From SARS to MERS, thrusting coronaviruses into the spotlight. Viruses. 2019;11(1):59.

24. Allard R, Leclerc P, Tremblay C, Tannenbaum TN. Diabetes and the severity of pandemic influenza A (H1N1) infection. Diabetes Care. 2010;33(7):1491e3.

25. Yan Y, Yang Y, Wang F, Ren H, Zhang S, Shi X, et al. Clinical characteristics and outcomes of patients with severe covid-19 with diabetes. BMJ Open Diabetes Res Care. 2020;8(1):e 001343

26. Kumar A, Arora A, Sharma P, Anikhindi SA, Bansal N, Singla V, et al. Is diabetes mellitus associated with mortality and severity of COVID-19? A meta-analysis. Diabetes Metab Syndr. 2020;14(4):535-545.

27. Huang I, Lim MA, Pranata R. Diabetes mellitus is associated with increased mortality and severity of disease in COVID-19 pneumonia - A systematic review, meta.analysis, and meta-regression. Diabetes Metab Syndr. 2020;14(4):395-403

28. McLaughlin T, Ackerman SE, Shen L, Engleman E. Role of innate and adaptive immunity in obesity-associated metabolic disease. J Clin Invest. 2017;127:5-13.

29. Vankadari N, Wilce JA. Emerging WuHan (COVID-19) coronavirus: glycan shield and structure prediction of spike glycoprotein and its interaction with human CD26. Emerg Microb Infect. 2020;9(1):601e4.

30. Singh AK, Gupta R, Ghosh A, Misra A. Diabetes in COVID-19: Prevalence, pathophysiology, prognosis and practical considerations. Diabetes Metab Syndr. 2020;14(4):303-310

31. lacobellis G. COVID-19 and Diabetes: can DPP4 inhibition play a role? Diabetes Res Clin Pract. 2020;162:108125.

32. Drucker DJ. Coronavirus infections and type 2 diabetes-shared pathways with therapeutic implications. Endocr Rev. 2020;41(3):bnaa011. 